\title{
Distintas posiciones éticas en Hécuba de Eurípides: el problema de la virtud
}

Different ethical positions in Euripides' Hecuba: the problem of virtue

Juan Tobias Nápoli

Universidad Nacional de La Plata, Argentina

jnapoli@huma.fahce.edu.ar

\section{ReSUMEN:}

Hay en Hécuba de Eurípides, esparcidas por toda la tragedia y en boca de distintos personajes, numerosas argumentaciones de carácter ético-filosófico. Estas argumentaciones recogen mejor las especulaciones de la sofística del siglo V que el modo de pensar de personajes que pertenecen a una época histórica arcaica y cuyas acciones y valoraciones fueran recogidas por la épica homérica. Incluso, estas argumentaciones resultan muchas veces contradictorias entre sí. Queremos fijar nuestra atención en algunas de ellas, como una manera de profundizar en la modalidad creativa del poeta.

Palabras Clave: Eurípides, Hécuba, ética, Agamenón, Odiseo.

\section{Abstract:}

There are in the Euripides' Hecuba, scattered throughout the tragedy and in the mouths of different characters, numerous arguments of an ethical-philosophical nature. These arguments better capture the speculation of 5th century sophistry than the way of thinking of characters who belong to an archaic historical period and whose actions and evaluations were collected by the Homeric epic. Even these arguments are often contradictory to each other. We want to focus our attention of some of them, as a way of deepening the poet's creative modality.

KEYWORDS: Euripides, Hecuba, ethics, Agamemnon, Odysseus.

Hécuba de Eurípides es una tragedia llena de sorpresas y originalidades. Además de modificar el mito, para presentarnos, entre otros detalles, por primera vez a Polidoro como hijo de Hécuba y no de Laóthoe; ${ }^{1}$ además de mostrarnos por primera vez las consecuencias de la guerra desde el punto de vista de los vencidos (antes aún que Troyanas) (Nápoli, 2014, pp. LXXI-CIII); además de mostrarnos el dolor de las mujeres (Hécuba, Polixena y las cautivas troyanas que forman el coro) en situaciones de dominación y esclavitud; ${ }^{2}$ además de arrastrarnos por el caleidoscopio de las honduras psicológicas del personaje de Hécuba, quien, como nueva Medea, pasa de víctima de la violencia masculina (capaz de granjearse nuestra simpatía) a convertirse en un demonio de furia y venganza, provocando espanto y rechazo; además de llevarnos, desde una perspectiva formal, a través de las distintas funciones sociales de Hécuba, quien pasa de suplicante a madre dolorida por el sacrificio de su hija, y de madre dolorida por el traicionero asesinato de su hijo a suplicante nuevamente, para terminar convertida en líder popular de una revuelta de mujeres vengativas; además de estas originalidades de trama y planteo, ${ }^{3}$ la obra encierra otros muchos temas de interés.

Por una parte, la consideración de la tragedia en su carácter genérico y en tanto obra de arte también ha sido debatida. Que no es una tragedia ha sido sugerido por Gellie (1980, pp. 30-44). Dudas similares aparecen en un trabajo de Rosenmeyer (1987, pp. 264-70). ${ }^{4}$ Más allá de esta postura extrema, ${ }^{5}$ otras posiciones críticas le conceden el papel central a la ironía como determinante de la estructura de la tragedia. ${ }^{6}$ F. Zeitlin (1991, p. 51-94), por ejemplo, considera que la obra es la menos consoladora de entre las tragedias de Eurípides, devolviéndole su más plena calificación como tragedia.

Por otra parte, hay detalles particularmente significativos: la descripción psicológicamente tan humana de las mujeres del coro, que nos relatan cómo se sorprenden con el asalto nocturno a la ciudad de Troya, presentado desde la perspectiva cotidiana de unas mujeres que realizan las ceremonias habituales antes de irse 
a la cama, reemplazando la ropa de fiesta y arreglándose el cabello frente al espejo, antes de acostarse al lado de sus esposos dormidos, dichosas luego de la aparente victoria de la ciudad después de un sitio de diez años (Nápoli, 2011, pp. 271-293).

Finalmente, esta verosimilitud en la presentación de los personajes no impide la aparición de una serie de anacronismos, totalmente contrarios a esta verosimilitud psicológica. Los críticos no han sabido justificar esta contradicción.

Entre estos anacronismos, deben citarse los dos agônes que encierra la tragedia. El primero de ellos, aunque no es un agón en el sentido pleno de la palabra, enfrenta a Hécuba con Odiseo entre los versos 251-321. Allí, Hécuba argumenta que Odiseo está quebrantando las leyes de hospitalidad, ${ }^{7}$ ya que la propia reina de Troya lo auxilió cuando el laertíada hizo una excursión secreta al interior de la ciudadela. Odiseo, que viene a buscar a Polixena para sacrificarla ante la tumba de Aquiles, ${ }^{8}$ argumentará, contraponiendo a la moral tradicional de la xenía, el supremo interés de la patria y la necesidad política de que los mejores hombres reciban el reconocimiento que sus acciones le ganaron. La discusión, llena de argumentos retóricos, parece fuera de lugar en relación con la situación dramática. El segundo agón, entre los versos 1109-1286, enfrenta a Hécuba con Poliméstor, con Agamenón como árbitro. Nuevamente, la retórica más propia de los sofistas que de los héroes homéricos aparece muy inadecuada para la situación dramática (Sealey, 1994).

Sin embargo, no queremos por ahora detenernos en estos agônes, bien estudiados por otra parte. Hay, esparcidas por toda la tragedia y en boca de distintos personajes, numerosas argumentaciones de carácter ético-filosófico, que recogen mejor las especulaciones de la sofística del siglo $\mathrm{V}$ que el modo de pensar de unos personajes que pertenecen a una época histórica arcaica y cuyas acciones y valoraciones fueran recogidas por la épica homérica. ${ }^{9}$ Incluso, estas argumentaciones resultan muchas veces contradictorias entre sí. Queremos fijar nuestra atención en algunas de ellas, como una manera de profundizar en la modalidad creativa del poeta.

La primera de estas reflexiones está en boca de Hécuba, en su súplica ante Agamenón. En los versos 798-805, la reina de Troya justificará delante de Agamenón su demanda de colaboración para poder vengarse de Poliméstor, con palabras que constituyen una cosmovisión y al mismo tiempo un programa ético:

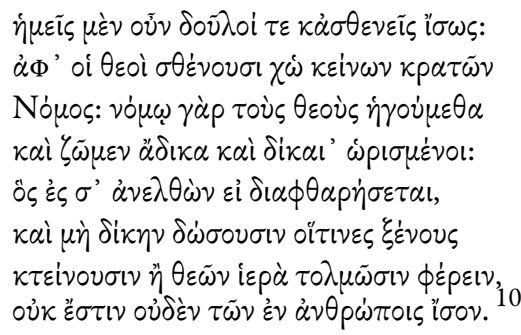

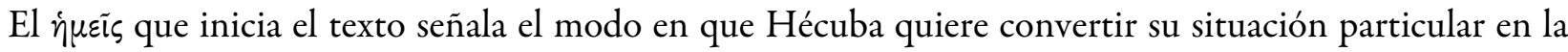
situación común de todos los hombres. Todos los hombres (no solo Hécuba, ni solo las mujeres troyanas) son esclavos y asténicos, carentes de fuerza. Esta idea será recurrente en la tragedia, ya que la misma Hécuba

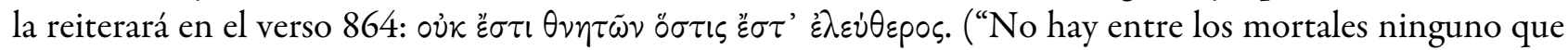
sea libre").

Quienes tienen fuerza verdaderamente son los dioses y por encima de ellos se encuentra el Nómos. Resulta difícil traducir aquí este concepto. A pesar de la mayúscula, no parece referirse a Nómos como personificación de las leyes, esposo de Eusébeia y padre de Dike, según lo recoge el Himno Órfico n 64 (Bernabé, 2004). Debe señalarse la incongruencia en el uso de la mayúscula, ya que el políptoto con nómos juega con el mismo 
concepto: o es siempre la personificación de las leyes (y lleva mayúscula en ambas ocasiones) o no lo es nunca. Creemos que Hécuba no está hablando de esta personificación. ¿Es aquí el Nómos, en cambio, como para los sofistas, una convención humana opuesta a la phýsis, según se ve, por ejemplo, en la leyenda del anillo de Giges en La República de Platón (II, 359a-360b) ? ${ }^{11}$ Si así fuera, Hécuba querría decir que el culto y la veneración a los dioses está subordinado a una fuerza convencional y puramente humana, a la imposibilidad de volvernos invisibles a su mirada escrutadora. ¿ O, por el contrario, el Nómos alude aquí a las instituciones de los antepasados, a la norma inveterada que rige profundamente la vida de los hombres, al nómos rey de todo, según lo describe Píndaro? (Sealey, 1994). Con matices, cualquiera de estas interpretaciones es anacrónica y deudora de la argumentación sofística, que convierte en convencional el culto a los dioses.

Postulamos una cuarta opción, más acorde con la presentación del personaje: ¿este Nómos, habitualmente interpretado en época clásica como la ley convencional, no podría referirse en realidad a una concepción más antigua, a esta ley del destino que, en Ilíada, tantas veces se impone, como acuerdo general de los dioses, por encima de la propia voluntad de Zeus? Chantraine nos señala que el verbo némo, igual que el sustantivo nómos, tiene un doble valor: por un lado, atribuir, repartir según el uso y la conveniencia, hacer una atribución regular; por otro lado, también implica disfrutar de lo atribuido o repartido. Así, por ejemplo, nómos puede ser tanto la acción de repartir la comida o la pastura como la pastura misma. De este doble valor del concepto provienen términos como nomeús (pastor) o nomás, los que deambulan en busca de pastura.

En este sentido, podemos justificar que el nómos al que se refiere Hécuba está constituido, a la manera homérica, por el acuerdo voluntario de los dioses, que atribuyen a cada uno el destino que le corresponde, y el propio destino, resultado de aquella atribución. Si el nómos, tanto como acuerdo general de los dioses cuanto como destino individual, gobierna sobre los dioses, el hombre, entonces, tiene bien merecida la calificación de esclavo. Esta vinculación con el pensamiento homérico hace que las palabras de Hécuba estén en sintonía con lo que puede esperarse de un personaje de los tiempos heroicos.

Si este nómos superior a los dioses puede identificarse con la concepción homérica del destino al que el propio Zeus está subordinado, nos encontraríamos entonces con una concepción ética tradicional. La novedad, sin embargo, está constituida por las consecuencias que expone Hécuba: ese destino superior a los dioses es la base de nuestro respeto a las divinidades; en consecuencia, la conducta de los dioses no es caprichosa, sino que responde a una organicidad cósmica; finalmente, la responsabilidad del hombre consiste en vivir a través del constante discernimiento acerca de qué cosa es justa y qué otra es injusta. Aunque la voluntad de los dioses, administradores del nómos, no sea clara en los casos concretos, igualmente la inteligencia humana debe esforzarse para discernir y obrar el bien. De este modo, el hombre, intérprete del nómos, tiene una doble responsabilidad: debe discernir intelectualmente en primer lugar cuáles son las cosas justas e injustas y, luego, debe obrar justamente y debe castigar los actos injustos. Se convierte así en responsable de su conducta en un doble sentido, ya que es responsable de realizar los actos justos y, al mismo tiempo, de hacerse responsable de que los actos injustos sean debidamente castigados. Tanto matar a un huésped como no castigar esta impiedad constituyen actos igualmente culpables. Este discernimiento intelectual e individual de lo justo y de lo injusto debe, por tanto, derivar en una acción concreta, independientemente de sus resultados. Se trata de la ética de la convicción, para expresarlo en términos de Max Weber, aunque entre los griegos estas concepciones constituyen de algún modo lo que se ha denominado el optimismo ético socrático.

Sin embargo, este optimismo socrático encuentra un límite en el controvertido tema de la educabilidad de la virtud. En otro anacronismo flagrante, Hécuba parece oponerse directamente al pensamiento platónicosocrático (el cual defiende la posibilidad de educar a los hombres en la virtud) en los versos 592-602:

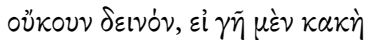

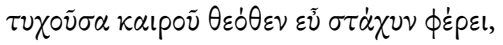

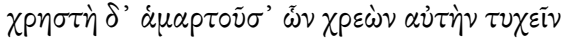




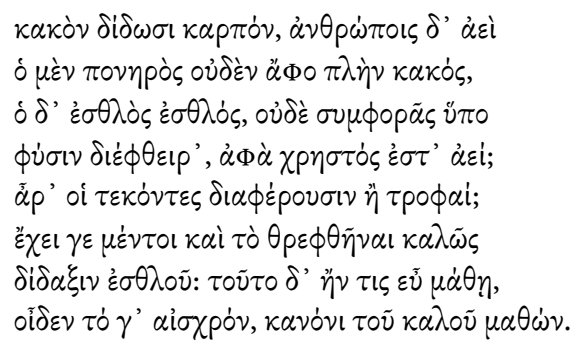

¿No es terrible acaso que una tierra, a pesar de ser mala, acertando por gracia de los dioses la ocasión propicia, produzca una buena espiga de trigo? ¿Y que, en cambio, una tierra provechosa, cuando carece de aquello que necesita, dé un mal fruto? ¿Y que entre los hombres siempre el que es pérfido ninguna otra cosa produzca excepto el mal? ¿Y que el noble solo produzca cosas nobles? ¿Y que no se destruya su naturaleza por la coyuntura externa, sino que sea siempre fructífero? ¿Difieren allí acaso los padres o la educación? Es verdad que el hecho de haber sido bien educado implica la enseñanza de la nobleza. Cuando alguien la ha aprendido bien, puede entonces discernir lo que es vergonzoso, después de medirlo con la vara de lo bello.

Hécuba utiliza el argumento de la buena tierra para contraponerlo con la conducta de los hombres. Sin embargo, complejiza la metáfora para poder desecharla y llegar por otro camino a la idea original. Ya en el Génesis, y repetido abundantemente en el Pentateuco y en el Libro de los Salmos, aparece la metáfora de la buena tierra que da un buen fruto. ${ }^{12}$ La buena tierra siempre da buen fruto, y Píndaro utilizará también esta metáfora expresada a través de la idea de la фuà. Es la idea aristocrática que afirma que la virtud es innata. Por ello, la metáfora de la buena tierra sirve para defender la nobleza de sangre. Sin embargo, Hécuba le agrega a la metáfora un elemento que la torna inaplicable a sus intenciones: las condiciones externas, que son capaces de cambiar la condición natural. Veámoslo con algún detalle.

La mala tierra puede dar buen fruto, cuando las condiciones externas acompañan; y la buena tierra podría dar mal fruto, si estas condiciones externas no son las apropiadas. La metáfora ha sido invertida y ya no sirve para justificar la nobleza de sangre. En cambio, entre los hombres ocurre algo muy diferente, ya que el pérfido siempre produce solamente el mal y el noble solo produce cosas nobles. El hombre noble no destruye su

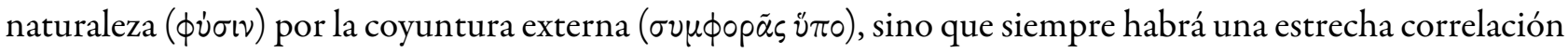
entre su condición y su obrar. En el hombre no se verifica la misma realidad que en la tierra. Sin embargo, Hécuba no es consecuente con su argumentación. En lugar de mostrar de qué manera influye la naturaleza sobre el hombre malo (que sería la continuidad natural de su argumentación), seguirá adelante con una sutil diferencia sobre lo que podría ocurrir entre los hombres nobles: los padres (oi $\tau \varepsilon k o ́ v \tau \varepsilon \varsigma$ ) y las educaciones

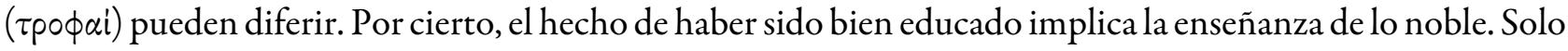
los padres nobles pueden enseñar la nobleza, pero no todos lo hacen. ¿En qué consiste enseñar la nobleza? Si alguien logra aprenderla, será capaz de conocer aquello que es vergonzoso: nuevamente, la idea intelectual del discernimiento individual, presente en el pasaje en las formas verbales oí $\delta \varepsilon v$ y $\mu \alpha \theta \dot{\omega} v$. Solo el noble bien educado puede, después de aprenderlo, conocer la virtud y discernir lo vergonzoso. La ética de la nobleza de sangre se manifiesta entonces, con argumentos novedosos, hasta límites cada vez más profundos. ¿Es esta la posición de Eurípides? Al menos, es la posición de un personaje, que se verá inmediatamente refutado por las argumentaciones de otros personajes.

Sin embargo, no es esta la posición constante del poeta. Ello puede verse en las numerosas declaraciones contrarias a esta idea. Así, por ejemplo, dirá Adrasto en Suplicantes, vv. 911-917:

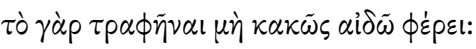

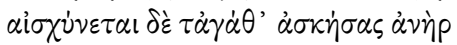

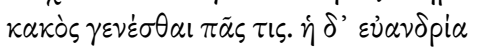

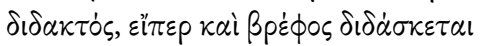

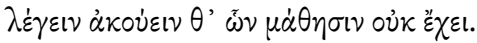

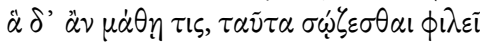

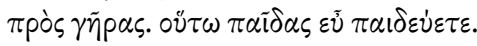


Ser educado de manera adecuada engendra sentido del honor. Todo varón que se ejercita en el bien se avergüenza de convertirse en cobarde. Es posible enseñar el vigor masculino, si el niño es enseñado a decir y a escuchar aquello de lo que no tiene conocimiento. Lo que alguien aprende de niño, lo guarda para sí hasta la vejez. Así, entonces, eduquen bien a sus hijos.

Evidentemente, la cuestión de la enseñanza de la virtud estaba en el centro del debate de la Atenas del siglo V. La posición tradicional y aristocrática (representada, por ejemplo, en las palabras de Hécuba) pretende que la virtud es innata. Sin embargo, el movimiento sofístico trae una nueva idea acerca de la educabilidad de la virtud. Aquí Adrasto, como hará el coro en Ifigenia en Áulide (vv. 558-572), sostendrá la idea más moderna. Adrasto destaca que el hábito, la práctica, la imitación inconsciente, son quienes pueden modificar las disposiciones innatas. Por ello hay que educar bien a los hijos, ya que esta educación modificará su naturaleza.

Sin embargo, como hemos dicho, cada personaje sostiene posiciones que corresponden con su situación dramática. Hécuba defiende la idea tradicional, porque el asesinato de sus hijos, modelos de nobleza, descubre la maldad innata de sus asesinos y justifica la venganza que está ya en marcha. No será raro que Odiseo y Poliméstor defiendan posiciones éticas diferentes.

En frente de estas concepciones novedosas, hay dos alternativas posibles. En primer lugar, la que exponía Odiseo en los versos 326-331:

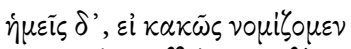

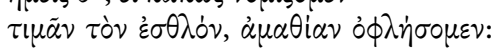

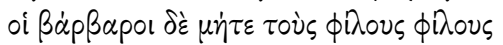

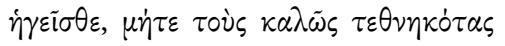

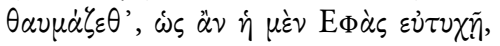

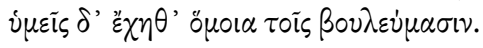
Nosotros, si estamos mal acostumbrados a honrar al hombre noble, pagaremos con nuestra ignorancia. Ustedes los bárbaros, en cambio, no quieren considerar amigos a sus amigos ni pretenden respetar a los que han muerto gloriosamente, para que, por un lado, la Hélade sea entonces afortunada y ustedes, por otro, tengan los bienes que corresponden a sus conductas.

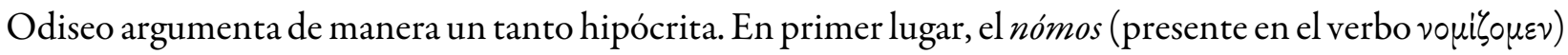
recupera su carácter de convención humana. Esta costumbre convencional, aunque a veces pueda parecer mala, consiste en honrar al hombre noble. Esto distingue a griegos de bárbaros: el resultado de esta costumbre es que los griegos pueden ser afortunados, mientras que los bárbaros, enigmáticamente, reciben cosas similares a sus determinaciones. Odiseo argumenta en línea con la ética de la responsabilidad (para reiterar la concepción de Max Weber): la acción de sacrificar a Polixena puede parecer mala (y el propio Odiseo lo reconoce); pero el resultado de esa mala acción es que la Hélade sea feliz. Y es el resultado de las acciones lo que se debe tener en cuenta para juzgar el carácter de una determinación ética. Ya no interesa el discernimiento intelectual e individual, el conocimiento o la nobleza. Odiseo bien podría representar a los políticos con los que debe convivir el propio poeta.

La segunda respuesta a la posición de Hécuba la ofrece Poliméstor, con una mirada distinta. Dirá entre los versos 956-960:

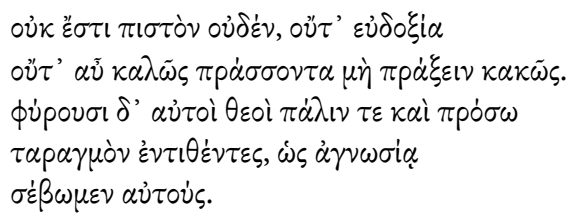

No hay nada en lo que podamos confiar: ni la buena fama, ni la garantía de que no vamos a padecer un mal si obramos bien. Los propios dioses confunden todo en una dirección y en otra, sembrando gran disturbio, para que los respetemos a causa de nuestra ignorancia. 
Para empezar, no hay en el mundo nada digno de confianza. Esta primera afirmación constituye ya una novedad en la cosmovisión griega. La imposibilidad de reconocer algún sentido en el orden cósmico implica una novedad más cercana al pensamiento de Protágoras que al de un rey tracio de la época de la guerra de Troya. ${ }^{13}$ La ausencia del nómos como principio ordenador deja a los dioses sin orden interno y les otorga una voluntad caprichosa.

Los propios dioses, de este modo, pueden confundir todas las cosas, mezclando lo húmedo con lo seco en una dirección y en la contraria. Como en el mito de los dos toneles del canto XXIV de Ilíada, para los hombres no hay ni buena fama ni buen obrar que le garanticen una vida feliz. Para los hombres está destinada, en consecuencia, una vida de males o, en el mejor de los casos, de bienes y males mezclados. Y este reparto es caprichoso, ya que los propios dioses siembran la confusión, porque quieren que los hombres, que son ignorantes, los respeten.

Es decir, si no fuera por la ignorancia humana, no habría respeto hacia los dioses. Y si no existiera la confusión que siembran los dioses, tampoco existiría la voluntad de los hombres de respetarlos. Es claro que la explicación de Poliméstor está de alguna manera condicionada por su situación particular: necesita justificar la traición hecha a Príamo y el modo en que traicionó la hospitalidad, asesinando a Polidoro y quedándose con sus riquezas. Ciertamente, la primera parte de la argumentación es consistente con la ética homérica: los dioses juegan con los hombres como un titiritero con sus marionetas. Sin embargo, la explicación tiene una segunda parte: en medio de este desorden cósmico, la ignorancia de los hombres los lleva a respetar y rendir culto a los dioses. La concepción de los dioses, como bastón para sostener la existencia humana en un mundo sin sentido, abona una concepción ética vinculada con un pragmatismo rotundo.

¿Cuál de estas posiciones éticas suscribiría Eurípides? ¿Cuál es su concepción acerca de la virtud? ¿Es innata o puede enseñarse? Los críticos han intentado, sin éxito, rastrear en todas sus tragedias un pensamiento coherente. Creemos que es una pretensión radicalmente inadecuada, porque se aparta de la modalidad creativa del dramaturgo. Eurípides renuncia deliberadamente a tomar partido: su pretensión se limita a presentar este mosaico de distintas posiciones y concepciones, que obligan al público a definir su propia postura. El carácter ficcional de la tragedia queda desenmascarado por el propio poeta, quien, en todo caso, nos muestra el modo en que los personajes, por un lado, argumentan y contraargumentan intelectualmente distintas posiciones éticas y, por el otro, luego no defienden esas posiciones con su obrar. Todos los personajes analizados argumentan intelectualmente sus posiciones con algún anacronismo flagrante. Ninguno de ellos sostiene su argumentación con una conducta equivalente. La propia Hécuba reaccionará finalmente con una sed de venganza y una crueldad difíciles de compatibilizar con sus posturas éticas previas.

La tragedia de Esquilo nos mostraba cómo el conflicto trágico deja al individuo sin posibilidades de obrar bien: Orestes tiene a disposición solo dos malas opciones. En Hécuba, en cambio, las opciones se multiplican. Sin embargo, cada uno de los personajes elige la conducta que más se adecua a sus intereses mezquinos, incluso en contra de sus propias posturas intelectuales. La tragedia que nos presenta el poeta consiste en vivir en un mundo donde la discusión intelectual no tiene el respaldo del obrar. Un mundo en donde las palabras y las cosas se han separado. Ese mundo que refleja Eurípides es profundamente trágico y, a un tiempo, profundamente moderno.

\section{REFERENCIAS}

Abrahamson, E. L. (1952). Euripides' Tragedy of Hecuba. TAPhA, 83, 120-29.

Adkins, A. W. (1966). Basic Greek Values in Euripides' Hecuba and Hercules Furens. CQ, 16, 193-219.

Arai, N. (1991). Hecuba's Revenge and Nomos: Euripides' Hecuba 798-801, 864-869. JCS, 39, 38-47.

Belfiore, E. S. (2000). Murder among Friends. Violation of Philian Greek Tragedy. Nueva York: Oxford University Press.

Bergson, L. (1971) Die Relativität der Werte im Frühwerk des Euripides. Uppsala: Lundquistska bokhandeln. 
Bernabé, A. (2004). Textos órficos y filosofía presocrática. Materiales para una comparación. Madrid: Editorial Trotta. Buxton, R. G. (1990). Bafflement in Greek Tragedy. Métis, 3, 41-51.

Cantarella, E. (1979). Norma e sanzione in Omero. Milan: Universitá degli studi.

Cantarella, E. (2000). Les peines de mort en Grèce et à Rome. Origines et fonctions des supplices capitaux dans l'Antiquité classique. Paris: Albin Michel.

Collard, C. (1991). Euripides. Hecuba. England: Warminster.

Conacher, D. J. (1967). Euripidean Drama: Myth, Theme and Structure. Toronto and London: University of Toronto Press.

Delebecque, E. (1951). Euripide et la guerre du Péloponnèse. Paris: C. Klincksieck.

Di Benedetto, V. (1971). Euripide: teatro e società. Torino: Einaudi.

Gall, D. (1997). Menschen, die zu Tieren Werden die Metamorphose in der 'Hekabe' des Euripides. Hermes, 125, 396-412.

Gellie, G. H. (1980). Hecuba and Tragedy. Antichthon, 14, 30-44.

Goossens, R. (1962). Euripide et Athèns. Bruselas: Académie Royale de Belgique.

Gregory, J. (1999). Euripides: Hecuba. Introduction, Text and commentary. Atlanta: Scholar Press.

Grube, G. M. A. (1941). The Drama of Euripides. London: Methuen \& co.

Hall, E. (1991). Inventing the Barbarian. Greek Self-Definition through Tragedy. Oxford: Oxford University Press.

Heath, M. (1987). Jure principem locum tenet: Euripides' Hecuba. BICS, 34, 40-68.

Hogan, J. C. (1972). Thucydides 3.52-68 and Euripides' Hecuba. Phoenix, 26, 241-57.

Kovacs, D. (1987). The Heroic Muse: Studies in the Hippolytus and Hecuba of Euripides. Baltimore: A. J. Ph.

López Férez, J. A. (1992). Eurípides. Tragedias, I. Madrid: Cátedra.

López Férez, J. A. (2000). Aquiles en Eurípides. En V. Pirenne-Delforge y E. Suárez de la Torre (Ed.), Héros et héroïnes dans les mythes et les cultes grecques. Actes du Colloque organisé à l'Université de Valladolid du 26 au 29 mai 1999 (pp. 149-166). Liége: Presses universitaires de Liège.

Macdowell, D. M. (1999). Athenian Homicide Law in the Age of the Orators. Manchester: Manchester University Press. Melchinger, S. (1973). Euripides. New York: Ungar Pub co.

Meridor, R. (1978). Hecuba's Revenge. Some Observations on Euripides' Hecuba. AJP, 99, 28-35.

Meridor, R. (1983). The Function of Polymestor's Crime in the Hecuba of Euripides. Eranos, 81, 13-20.

Michelakis, P. (2002). Achilles in Greek Tragedy. Cambridge: Cambridge University Press.

Michelini, A. N. (1987). Euripides and the Tragic Tradition. Madison: The University of Wisconsin Press.

Mossman, J. (1992). Wild Justice: A Study of Euripides' Hecuba. Oxford: Oxford University Press.

Nápoli,J. T. (2011). La destrucción de Troya en Hécuba, Troyanas e Ifigenia en Aulide de Eurípides. Análisis metafórico de tres pasajes líricos. En L. Galán y M. Buisel (Ed.), Itinera: Homenaje al Dr. Alberto J. Vaccaro (pp. 271-293. xxxx). La Plata: Al Margen.

Nápoli, J. T. (2014). Euripides. Tragedias II. Buenos Aires: Colihue.

Norwood, G. (1954). Essay on Euripidean Drama. Berkeley-London: Cambridge University Press.

Nussbaum, M. (1986). The Fragility of Goodness. Luck and Ethics in Greek Tragedy and Philosophy. Cambridge: Cambridge University Press.

Patin, H. (1913). Etudes sur les Tragiques Grecs. Euripide, 2 vols., Paris: Les Belles Lettres.

Pébarthe, CH. (1999). Thassos, l'empire d'Athènes et les emporia de Thrace. ZPE, 126, 131-145.

Perdicoyianni, H. (1993). Le vocabulaire de la douleur dans l' Hécube et les Troyennes d' Euripide, Les Etudes Classiques, $\operatorname{LXI}(3), 195-204$.

Pippin Burnett, A. (1994). Hekabe the Dog. Arethusa, 27(2), 151-164. 
Pippin Burnett, A. (1998). Revenge in Attic and Later Tragedy. Berkeley, Los Angeles, Londres: University of California Press.

Reckford, K. J. y Lembke, J. (1991). Introduction to Euripides' Hecuba. Oxford: Oxford University Press.

Rosenmeyer, T. G. (1987). Euripides' Hecuba: Horror Story or Tragedy? En First International Meeting of Ancient Greek Drama (pp. 264-70). Athens

Rudhardt, J. (1992). Notions fondamentales de la pensée religieuse et actes constitutifs du culte dans la Grèce classique. Genève: Droz.

Saï, S. (1984). La tragédie de la vengeance. En G. Courtois (Ed.), La vengeance. Études d'ethnologie, d'histoire et de philosophie. Vol. 4: La vengeance dans la pensée occidentale (pp. 47-90). París: Editions Cujas.

Santiago Álvarez, R. A. (1999). Clitemnestra / Clitemestra: ¿Adaptación de un nombre a la evolución del personaje? En K. Andersen; J. V. Bañuls y F. De Martino (Ed.), El teatre, eina politica. Homenatge de la Universitat de València a Bertolt Brecht ambmotiu del Centenari del seu naixement. 6-9 de maig de 1998 (pp. 351-370). Bari.

Santiago Álvarez, R. A. (2004). La familia léxica de xénos en Homero: usos y significados, II (Odisea). Faventia, 26(2), $25-42$.

Sealey, R. (1994). The justice of the Greeks. Ann Arbor: University of Michigan Press.

Segal, C. (1990). Golden Armor and Servil Robes: Heroism and Metamorphosis in Hecuba of Euripides. AJPh, 111, 304-17.

Segal, C. (1993). Euripides and the Poetic of Sorrow. Art, Gender and Commemoration in Alcestis, Hippolytus and Hecuba. Durham and London: Duke University Press.

Spranger, J. A. (1927). The problem of the Hecuba. CQ, XXI, 155-58.

Stanton, G. R. (1995). Aristocratic obligation in Euripides' Hecuba. Mnemosyne, 48(1), 11-33.

Tarkow, T. A. (1984). Tragedy and Transformation: Parent and Child in Euripides' Hecuba. Maia, 36, 123-36.

Thalmann, W. G. (1993). Euripides and Aeschylus: The Case of the Hekabe. ClAnt, 12, 126-159.

Tovar, A. (1960). Eurípides. Tragedias. Las Bacantes-Hécuba, Volumen II. Barcelona: Alma Mater.

Vellacott, P. (1975). Ironic Drama: A Study of Euripides' Method and Meaning. Cambridge: Cambridge University Press.

Webster, T. B. L. (1967). The Tragedies of Euripides. London: Methuen young books.

Whitman, C. H. (1974). Euripides and the Full Circle of Myth. Cambridge: Cambridge University Press.

Zeitlin, F. I. (1991). Euripides' Hekabe and the somatics of Dionysos drama. Ramus, 20, 53-94.

\section{Notas}

1 Cf. Iliada, XXII, vv. 46-48. Un análisis más profundo puede verse en Meridor (1983, pp. 13-20).

2 Es lo que postula Grube (1941, pp. 82-84).

3 Todas estas cuestiones dan origen a distintas interpretaciones de la tragedia. La postura psicologista sostiene que la obra constituye un análisis psicológico de los personajes en situaciones de tensión extrema. Hélène Perdicoyianni (1993, pp. 195-204), entre otros (cf. Patin, 1913, quien dedica sus capítulos X, XI y XII a Troyanas y Hécuba en conjunto: volumen I, pp. 331-427), postula que el poeta haría, en Hécuba y Troyanas, un similar esbozo psicológico acerca del estado de los miembros de la antigua familia real y de las mujeres troyanas que componen el coro, así como de sus reacciones emotivas frente a su lamentable destino. La postura político-pacifista sostiene que la obra es un grito en favor del pacifismo o una crítica a los demagogos atenienses. Así, Abrahamson (1952, pp. 120-129) la consideró un reflejo de la realidad de un campo de concentración, en la que Hécuba llega a convertirse en una bestia cuando es torturada más allá de lo que es posible resistir para un ser humano. Di Benedetto (1971, pp. 138-144) sigue, aunque moderadamente, la línea de análisis político de Goossens (1962), y afirma que la obra constituye el primer ejemplo en el que Eurípides desarrolla un ataque explícito en contra de los demagogos que prometen aquello que el interlocutor quiere escuchar, pero ejecutan siempre lo que les conviene. Vellacott (1975, pp. 162-63) considera que la tragedia es una implacable y detallada comprobación de la corrupción que resulta de la guerra. Posiciones similares sostiene Thalmann (1993, pp. 126-159). La postura individualista señala que la obra retrata la declinación de un carácter individual que, en otras circunstancias, 
habría podido ser bueno. Se trataría, en consecuencia, de denunciar de qué manera una ley corrupta y unas condiciones generales embrutecedoras serían capaces de deformar incluso a una naturaleza noble, como es el caso de la piadosa mater dolorosa de esta tragedia, que, en función de estas crueles realidades, quedaría reducida al más bajo común denominador humano. Cf. al respecto Nussbaum (1986, pp. 397-421) y Segal (1990, pp. 304-17). También Collard (1991, p. 21) sugiere que, en Hécuba, Eurípides hace un examen de los principios morales que todos los caracteres evidencian de manera diferente y, además, un estudio particular de un carácter específico. Collard (1991, p. 30) retoma también las posiciones de Hall (1989, especialmente el capítulo 5, en donde estudia las inversiones realizadas por Eurípides acerca de los valores morales según los atribuye a griegos y bárbaros). La situación del bárbaro Poliméstor en su reclamo de amistad y lealtad con Agamenón y la consideración de la venganza de Hécuba contra Poliméstor como un acto más bárbaro aún que el del rey bárbaro, ambas cuestiones han sido planteadas desde esta perspectiva psicológica individual. Para decirlo de manera concluyente en las palabras de Bergson: el fundamento de la representación trágica estaría constituido, en estas lecturas, por el desarrollo psíquico del personaje principal, que, desde la prisionera sin poder y aniquilada, se convierte en una vengadora poderosa y desconsiderada (cf. Bergson, 1971, pp. 65-73). En 1987, Kovacs (cap. 3) da una nueva visión: la obra plantearía una reafirmación de los valores heroicos, en contra de la visión que sugiere un significado irónico debajo de la superficie del diálogo.

4 Adkins (1966, pp. 193-219) argumenta que, lejos de rechazar los valores populares griegos, en Hécuba Eurípides reafirma el valor tradicional de honrar a los amigos y extiende el uso tradicional y pertinente de algunos términos referidos a lo que no debe hacerse.

5 Tal vez representada también por Buxton (1990, pp. 41-51). El sentido de la tragedia consistiría en admitir la existencia de la frustración como parte integrante de la vida.

6 El primero en hablar de la ironía en Hécuba es Conacher (1967). Lo siguen Whitman (1974), Vellacott (1975) y Michelini (1987). Hogan (1972, pp. 241-57), ve ironía en el tratamiento de Agamenón. Tarkow (1984, pp. 123-36) percibe ironía en el énfasis puesto por el poeta en destacar la transferencia de obligaciones de generación en generación y en el carácter degradado de esta transferencia, ya que contrasta el colapso moral de Hécuba cuando ejecuta su venganza con la pureza moral de Polixena.

7 Sobre la cuestión de la hospitalidad cf. Belfiore (1991) y Santiago Álvarez (2004, pp. 25-42).

8 Sobre Aquiles en Hécuba, cf. López Férez (2000, pp. 149-166) y Michelakis (2002).

9 Cf., principalmente, Adkins (1966), Nusbaum (1986) y Pippin Burnet (1998). También puede verse Cantarella (1979), Saïd (1984, pp. 47-90), Heath (1987, pp. 40-68) y Macdowell (1992).

10 Las citas griegas están tomadas de la edición de Collard (1991). También hemos confrontado las traducciones y ediciones de Tovar (1960), Melchinger (1973), López Férez (1992) y Gregory (1999). Las traducciones siempre son nuestras.

11 Cf. Arai (1991, pp. 38-47) y Stanton (1995, pp. 11-33).

12 Génesis 1: 11; Génesis 1: 24; Levítico 25: 19; Levítico 26: 4-5; Salmos 67:6; Salmos 85: 12; Salmos 72: 16; Números 13: 20; Deuteronomio 1: 25; Deuteronomio 28: 4; Deuteronomio 28: 11; Deuteronomio 30: 9, entre otros.

13 Sobre la cuestión de la visión de Tracia por los poetas griegos cf. Hall (1991) y, principalmente, Pébarthe (1999, pp. 131-145). 